\title{
Emerging horizons in anaesthetic practice: a pharmacological update
}

\author{
R. Sudar Codi*, K. Manimekalai
}

Department of Pharmacology, Mahatma Gandhi Medical College \& Research Institute, Pondicherry, India

Received: 06 December 2017 Accepted: 04 January 2018

\section{*Correspondence to:}

Dr. R. Sudar Codi,

Email: sudarcodi@gmail.com

Copyright: (C) the author(s), publisher and licensee Medip Academy. This is an openaccess article distributed under the terms of the Creative Commons Attribution NonCommercial License, which permits unrestricted noncommercial use, distribution, and reproduction in any medium, provided the original work is properly cited.

\begin{abstract}
Anesthesiologists are in search for new drugs possessing properties like rapid onset of action, minimal residual effects, better hemodynamic stability, organ independent metabolism and cost effective. Structural alterations of the currently available compounds or newer formulations of the older ones or newer anaesthetic drug delivery system will be an useful alternative to newer discovery by reducing the cost and time. Tapentadol is a centrally acting $\mu$ opioid receptor (MOR) agonist with selective norepinephrine reuptake inhibition, approved by US FDA for treating moderate to severe acute pain in adults more than 18 years of age. Sugammadex, a novel selective relaxant binding agent to reverse steroidal neuromuscular blockers is recently approved by the European Union. Gantacurium, a rapid and ultra short acting non depolarizing neuromuscular blocker, inactivated rapidly by the adduction of non essential amino acid cysteine to the gantacurium molecule is in clinical trials. Remimazolam is a new drug in clinical trials that has a rapid onset of action like midazolam and is metabolized by non specific tissue esterases like remifentanil and expected to have a promising future. Liposomal Bupivacaine is approved by FDA in October 2011 that uses bupivacaine in liposomal vesicles to extend the duration of analgesia upto 72 hours and reduces the opioid use in the post operative period. Methoxy carbonyl carboetomidate is in clinical trials that combines the advantages of MOC etomidate and carboetomidate. Hence anaesthesiology is marching towards a bright pathway with new soft drugs coming up making not only anaesthesiology soft but also pharmacology.
\end{abstract}

Keywords: Gantacurium, Methoxy carbonyl carboetomidate, Remimazolam, Sugammadex, Tapentadol

\section{INTRODUCTION}

Anaesthesiology is a branch of medicine that deals with unconscious patients, who cannot give a verbal response even in life threatening situations. Hence pharmacokinetic and pharmacodynamic properties of the drugs play a vital role in handling this altered physiological state. Therefore, anesthesiologists seek for drugs possessing properties like rapid onset of action, minimal residual effects, better hemodynamic stability, organ independent metabolism and inexpensive. ${ }^{1}$

On the other hand, newer drug discovery in the pharmaceutical industry takes million dollars and a decade time that leaves the anaesthesiologists at stress to tackle the patient condition with the available drugs.

Hence structural alterations of the currently available compounds or newer formulations of the older ones or newer anaesthetic drug delivery system will be a useful alternative to new drug discovery by reducing the money and time expenditure but fulfil the dreams of the anaesthesiologists for an ideal anesthetic agent. Though many drugs like dexmedetomidine, remifentanil, ropivacaine have recently come up, there are many soft drugs awaiting to change the scenario of anaesthetic practice. 
This narrative review summarizes the list of those emerging drugs that is expected to make a breakthrough in anesthetic practice. It is based on literature search in PubMed and Google Scholar Databases and is discussed under the following headings.

I. Recent new drug approvals

II. Newer drugs in clinical trials

III. Newer formulations of the existing ones.

\section{RECENT NEW DRUG APPROVALS}

Tapentadol is a centrally acting $\mu$ opioid receptor (MOR) agonist with selective norepinephrine reuptake inhibition, approved by US FDA in 2008 and by the Drug Controller General India (DCGI) for use in India in 2011..$^{2,3}$ It is indicated for treating moderate to severe acute pain in adults more than 18 years of age. ${ }^{4}$ Though it has low affinity for the MOR, it is only 2-3 times less potent than morphine and thus the analgesic efficacy is attributed to the selective norepinephrine reuptake inhibition. It undergoes first order kinetics with a plasma half life of 4 hours, hence there is no cumulative effect. Unlike tramadol, tapentadol does not produce active metabolites, hence there is less chance of overdosing, toxicity and drug interactions. It is a schedule II drug and can be prescribed only under supervision to prevent opioid dependence. It is a category $\mathrm{C}$ drug, hence its safety in pregnant and lactating mothers is of concern. ${ }^{5}$

\section{Sugammadex}

After the surgical procedure is over, skeletal muscle relaxation is reversed by neostigimine, an anticholinesterase inhibitor that causes bradycardia and hypotension. This is overcome by the use of anticholinergics like atropine and glycopyrolate whose use is limited due to side effects like tachycardia, dry mouth, urinary retention, constipation etc.

To overcome these difficulties in recovering the patient from anaesthesia, Sugammadex, a novel selective relaxant binding agent to reverse steroidal neuromuscular blockers is recently approved by the Eurpean Union but not by the US FDA.

Sugammadex is a modified cyclodextrin molecule molecule with a hydrophobic core and a hydrophilic exterior. $^{6}$ It forms very tight complexes with steroidal neuromuscular blockers like rocuronium, vecuronium, pancuronium and acts as an irreversible chelating agent. It undergoes chemical encapsulation by which hydrophobic interactions with muscle relaxant molecule traps the drug into the cyclodextrin cavity called the doughnut hole and forms an water soluble complex. ${ }^{7}$ It has no effect on anticholinesterase. It is biologically inactive and does not bind to plasma proteins, hence safe and well tolerated. It is eliminated by the kidneys. It is administered in the dose of $2-4 \mathrm{mg} / \mathrm{kg}$ iv. Since sugammadex does not act on nicotinic receptors or metabolized by acetylcholineesterase, they do not produce significant side effects. It is contraindicated in pregnant women and children as sufficient data is unavailable.

There were no significant drug interactions between sugammadex and endogenous steroidal hormones or steroidal drugs because the quartenary $\mathrm{N}+$ compound present in the steroidal relaxant rocuronium or vecuronium combines with sugammadex but the endogenous steroids do not possess the quartenary $\mathrm{N}+$, hence bind with low affinity with sugammadex as it is not clinically significant.

Hence sugammadex eliminates the need for using conventional anticholineesterases and anticholinergics, thereby decrease post operative muscle weakness and anaesthesiologists need not worry about bringing the TOF (Train of Four) count to one at the end of surgery.

Phase III 'Signal Trial' was done on patients undergoing surgery and received either sugammadex or conventional neostigmine with glycopyrolate for reversal of muscle relaxant. ${ }^{8}$ They found that the mean time to recovery of TOF ratio to 0.9 with sugammadex was 2.9 min compared to 50.4 min with neostigmine and glycopyrolate and was found to be highly statistically significant $(\mathrm{P}<0.0001)$. Another phase III 'Spectrum trial' revealed that $1.2 \mathrm{mg} / \mathrm{kg}$ iv of Rocuronium followed by $16 \mathrm{mcg} / \mathrm{kg}$ of sugammadex provide faster recovery than $1 \mathrm{mg} / \mathrm{kg}$ iv of succinylcholine and found to be highly statistically significant $(\mathrm{P}<0.0001) .{ }^{9}$ Hence sugammadex will find a better and bright future after approval by US FDA.

\section{DRUGS IN CLINICAL TRIALS}

\section{Gantacurium}

Though there are numerous neuromuscular blockers (NMBs) in use, there is continuous ongoing search for a drug that has rapid onset of action like succinylcholine with shorter duration of action like mivacurium that ultimately result in minimal residual neuromuscular blockade. Though Rocuronium has rapid onset of action, large doses are needed for the therapeutic effect, hence post operative neuromuscular blockade occurs.

Therefore, clinical trials are being conducted on a new isoquinoline compound Gantacurium, a rapid and ultra short acting non depolarizing neuromuscular blocker which is neither inactivated by the kidney nor by the liver. ${ }^{10}$ It is metabolized by two routes. It is inactivated rapidly by the adduction of non essential amino acid cysteine to the gantacurium molecule at the central fumarate double bond so that it is unable to bind to the acetylcholine receptor. It is also inactivated slowly by alkaline ester hydrolysis that yields inactive metabolites.

The action of Gantacurium is antagonized by neostigmine and L-cysteine. Moreover, recovery is faster with Gantacurium due to the presence of chlorine at the fumarate double bond in gantacurium. Though 
Gantacurium causes histamine release leading to transient fall in BP, it does not interact with the muscarinic receptors in the airway, hence bronchospasm does not occur.

Studies in human volunteers reveal that $0.3 \mathrm{mg} / \mathrm{kg}$ of gantacurium i.v causes paralysis of laryngeal adductors and adductor pollicis in 1.1 and 1.7 minutes respectively and $95 \% \mathrm{~T} 1$ suppression was seen at 12.9 and 12.2 minutes respectively. ${ }^{11}$ Hence Gantacurium will be a promising neuromuscular blocker in the near future.

\section{Remimazolam}

Yet another soft drug in anaesthesia that is expected to be a corner stone in anesthetic pharmacology is Remimazolam. Remimazolam is a new drug in clinical trials that combine the properties of two unique drugs namely midazolam and remifentanil. ${ }^{12}$

Remimazolam is a benzodiazepine that acts on GABAalpha receptors, has a rapid onset of action like midazolam and is metabolized by nonspecific tissue esterases like remifentanil. ${ }^{13}$ The carboxylic ester linkage in the remifentanil structure is responsible for the metabolism by nonspecific tissue esterases in the blood to inactive metabolite, It undergoes dose and organ independent metabolism by ester hydrolysis. It follows first order kinetics and can be safely used in patients with renal or hepatic impairment.it also has minimal residual side effects and has less propensity to cause apnoea. Availability of Flumazenil as an antidote to antagonize remimazolam is yet another important advantage.

Phase IIa clinical trials with remimazolam revealed that the time to recovery from anaesthesia was shorter than midazolam in patients undergoing upper gastrointestinal endoscopies. $^{14}$

Hence remimazolam with its unique properties is expected to have a long stay in the pharmaceutical market.

\section{NEWER FORMULATIONS OF OLDER ONES}

\section{Liposomal bupivacaine}

There is immense research on newer drug delivery system and newer formulations to deliver the already existing drugs in order to improve the pharmacokinetic and pharmacodynamic properties of the drug.

Recently, a novel local anaesthetic formulation Liposomal Bupivacaine is approved by FDA in October 2011 that uses bupivacaine in liposomal vesicles to extend the duration of analgesia upto 72 hours and reduces the opioid use in the post operative period. ${ }^{15,16}$ This new innovator drug is manufactured by Pacira Pharmaceuticals under the trade name of 'Exparel'.

Exparel releases Bupivacaine by Depo Foam technology. This drug delivery system covers the drug molecule with phospholipid bilayers and slowly releases the drug over a prolonged period of time. ${ }^{17}$

\section{MOC - carboetomidate}

Methoxy carbonyl etomidate is emerging as a soft drug in anaesthesia like that of esmolol and remifentanil. ${ }^{18}$ It is in clinical trials and has a distinct advantage of metabolism by non specific tissue esterases. Yet another drug is in clinical trials named Carboetomidate does not have significant adreno cortical suppression. ${ }^{19}$ Hence Methoxy carbonyl carboetomidate is in clinical trials that combines the advantages of MOC etomidate and carboetomidate and is expected to stand long in the pharmaceutical market.

\section{CONCLUSION}

Hence anaesthesiology is marching towards a bright pathway with new soft drugs coming up making not only anaesthesiology soft but also pharmacology. Also chiral drugs are blooming up in anaesthesiology that will soon flood up the market because of the comparatively decreased cost in its development. Not only the soft drugs and chiral drugs, but also the pharmacogenomics of anaesthetic drugs and personalized anaesthesia will soon revolutionise the field of anesthesiology and make an important milestone.

Funding: No funding sources

Conflict of interest: None declared

Ethical approval: Not required

\section{REFERENCES}

1. Heitz JW, Witkowski T, Viscusi ER. New and emerging analgesics and analgesic technologies for acute pain management. Current Opinion in Anesthesiology. 2009;22(5):608-17.

2. Afilalo M, Stegmann JU, Upmalis D. Tapentadol immediate release: A new treatment option for acute pain management. J Pain Res. 2010;3:1-9.

3. Power. An update on analgesics. $\mathrm{Br} \mathrm{J}$ Anaesth. 2011;107(1):19-24.

4. Wade WE, Spruill WJ. Tapentadol hydrochloride: a centrally acting oral analgesic. Clin Ther. 2009;31(12):2804-18.

5. Singh DR, Nag K, Shetti AN, Krishnaveni N. Tapentadol hydrochloride: A novel analgesic. Saudi J Anaesth. 2013 Jul-Sep;7(3):322-6.

6. Tayal G, Kundra S, Grewal A. Sugammadex - New Neuromuscular Block Reversal. J Anaesth Clin Pharmacol. 2008;24(2):211-4.

7. Sorgenfrei IF, Norrild K, Larsen PB, Stensballe J, Ostergaard D, Prins ME, et al. Reversal of Rocuronium-induced Neuromuscular Block by the Selective Relaxant Binding Agent Sugammadex A Dose-finding and Safety Study. The Journal of the American Society of Anesthesiologists. 2006 Apr 1;104(4):667-74. 
8. Bom A, Bradley M, Cameron K, Clark JK, van Egmond J, Feilden $\mathrm{H}$, et al. A novel concept of reversing neuromuscular block: chemical encapsulation of rocuronium bromide by a cyclodextrin-based synthetic host. Angewandte Chemie. 2002 Jan 18;114(2):275-80.

9. Sparr HJ, Vermeyen KM, Beaufort AM, Rietbergen H, Proost JH, Saldien V, et al. Early reversal of profound rocuronium-induced neuromuscular blockade by sugammadex in a randomized multicenter study. Anesthesiology. 2007 May;106(5):935-43.

10. Lien CA. Development and potential clinical impact of ultra-short acting neuromuscular blocking agents. Br J Anaesth 2011;107(1):60-71.

11. Belmont MR, Lien CA, Tjan J, Bradley E, Stein B, Patel SS, et al. Clinical pharmacology of GW280430A in humans. Anesthesiology: The Journal of the American Society of Anesthesiologists. 2004 Apr 1;100(4):768-73.

12. Sneyd JR, Wright PCM, Cross M, Thompson P, Voortman G, Weideman MM, et al. Administration to man of ORG 21465 a water soluble steroid intravenous anaesthetic agent. British Journal of Anaesthesia. 1997;79:427-32.

13. Kilpatrick GJ, McIntyre MS, Lovell GG, Wiard RP, Feldman PL, Tilbrook GS. CNS 7056: A Novel UltraShort-Acting Benzodiazepine. Anesthesiology. 2007;107:60-6.
14. Rogers WK, McDowell TS. Remimazolam, a shortacting $\mathrm{GABA}(\mathrm{A})$ receptor agonist for intravenous sedation and/or anesthesia in day-case surgical and non-surgical procedures. I Drugs. 2010;13:929-37.

15. Praveen C, Kennneth CC. Liposomal bupivacaine: a review of a new bupivacaine formulation. J Pain Res. 2012;5:257-64.

16. Grant GJ, Barenholz Y, Bolotin EM. A novel liposomal bupivacaine formulation to produce ultralong acting analgesia. Anesthesiology. 2004;101(1):133-7.

17. Boogaerts. JG, Lafont. ND, Declercq AG. Epidural administration of liposome-associated bupivacaine for the management of postsurgical pain: a first study, Journal of Clinical Anesthesia. 1994;6(4):315-20.

18. Cotten JF, Hussain SS, Forman SA, Miller KW, Kelly EW, Nguyen HH, et al. A Novel Rapidly Metabolized and Ultra-short-acting Etomidate Analogue that does not produce prolonged Adrenocortical Suppression. Anesthesiology. 2009;111:240-9.

19. Forman SA. Clinical and Molecular Pharmacology of Etomidate. Anesthesiology. 2011;114:695-707.

Cite this article as: Codi RS, Manimekalai K. Emerging horizons in anaesthetic practice: a pharmacological update. Int J Basic Clin Pharmacol 2018;7:206-9. 